\title{
EDUCAÇÃO FINANCEIRA: PAPEL E IMPORTÂNCIA NO CAMPO ESCOLAR
}

\section{ARTIGO ORIGINAL}

GONÇALVES, Fábio José Domingues Poari ${ }^{1}$, CAMPANO, Patrícia Coelho², MOREIRA, Eline Dias ${ }^{3}$

GONÇALVES, Fábio José Domingues Poari. CAMPANO, Patrícia Coelho. MOREIRA, Eline Dias. Educação financeira: papel e importância no campo escolar. Revista Científica Multidisciplinar Núcleo do Conhecimento. Ano 06, Ed. 05, Vol. 09, pp. 77-98. Maio de 2021. ISSN: 2448-0959, Link de acesso: https://www.nucleodoconhecimento.com.br/educacao/campo-escolar, DOI: 10.32749/nucleodoconhecimento.com.br/educacao/campo-escolar

\section{RESUMO}

Este artigo tem por finalidade auxiliar de forma colaborativa o entendimento da Educação Financeira no âmbito escolar e na continuidade da vida acadêmica do alunado. Sabe-se que o uso do dinheiro, quando aplicado de forma adequada, gera impacto positivo na sociedade e alavanca a economia. $\mathrm{O}$ tratamento adequado das finanças no cotidiano apoia-se em valores como a sustentabilidade, cidadania, consciência ambiental, entre outros. Neste trabalho, apresentaremos a pesquisa realizada em uma escola sobre o tema Educação Financeira com o intuito de avaliar o conhecimento sobre o assunto, e como nossos professores, juntamente com as instituições que ministram aula, se organizam para apresentar a Educação Financeira em sala de aula. Nos dias de hoje é de suma importância que assuntos ligados às questões financeiras sejam tratados com especial atenção visto que dados apontam crescimento do endividamento da população. Será apresentado propostas de intervenções desde a educação infantil até o ensino médio com a

\footnotetext{
${ }^{1}$ Licenciatura em Matemática.

2 Licenciatura em Matemática.

${ }^{3}$ Orientadora. Doutorado em Educação Matemática.
} 
finalidade de ensinar os futuros adultos a respeitar e valorizar o dinheiro, bem como o seu uso consciente e abordar o tema com um olhar pedagógico, lúdico e prazeroso. $\mathrm{O}$ objetivo é expandir o conhecimento adquirido em sala de aula para a casa, afim de educar, conscientizar e melhorar a situação dos familiares de tal maneira que reflita na comunidade onde vivem. A metodologia utilizada na pesquisa bibliográfica foi desenvolvida com base em material já elaborado, constituído principalmente de livros e artigos científicos. Utilizou-se do estudo de casos, estudo exploratório, coleta de dados de natureza qualitativa-quantitativa.

Palavra-chave: Adolescentes, Educação Financeira, Escola, Matemática.

\section{INTRODUÇÃO}

Nos dias de hoje, há poucas pesquisas em Educação Financeira no Brasil, oriundo da falta desse ensinamento vindo dos pais que provavelmente também não obtiveram acesso a mesma, da escola e da própria sociedade.

Com isso, muitas famílias estão endividadas, pois não sabem lidar com suas finanças por não ter conhecimento de uma educação financeira adequada.

Diante da situação do endividamento acredita-se na necessidade de implementar a Educação Financeira no campo escolar desde a educação infantil até o ensino médio.

Com isso, o aluno adquire um importante conhecimento sobre planejamento financeiro obtendo a capacidade de transferi-los a geração futura e tornar a sociedade mais equilibrada financeiramente.

Conforme, D’Aquino (2008), o propósito de educar financeiramente os jovens em relação a como lidar com o dinheiro foca-se na construção de uma maturidade financeira.

Nesse artigo pretende-se mostrar a Educação Financeira de forma pedagógica desenvolvendo uma alternativa de Ensino Modelagem Matemática, leituras infantis 
como propostas de intervenção, tornando-a mais próxima da realidade dos educandos.

Apresentaremos a definição, o objetivo e a importância da Educação Financeira para a nossa vida cotidiana.

\section{DESENVOLVIMENTO}

\subsection{EDUCAÇÃO FINANCEIRA}

Quando falamos em Educação, logo nos vem à mente estudos, salas de aula, professores, alunos e tudo que remete a esse contexto, porém quase nunca ou nunca pensamos nela como uma forma de resolver os problemas financeiros, ou garantir um ganho, "poupar". Estamos falando de Educação Financeira, que pode ser confundida facilmente com Matemática Financeira.

Para sanar a dúvida entre uma e outra é preciso saber que a Educação Financeira tem por finalidade auxiliar os consumidores a administrar seus rendimentos e suas decisões (poupar/investir). Já a Matemática Financeira, aplica conceitos matemáticos em uma série de análises financeiras que está ligada na questão dinheiro e tempo (juros e inflação).

A Educação Financeira quando recebe um olhar pedagógico é apresentada de forma reflexiva, contribui para melhor formação de nossos alunos, garantido melhores condições de uma vida saudável, isso nos mostra tamanha importância de se conhecer melhor o assunto e conscientizar a população escolar desde a primeira faixa etária até sua formação adulta a respeito da utilização do dinheiro de forma sustentável.

[...] logo elas poderão ter um futuro mais tranquilo, menos incerto e menos dependente de programas, como a previdência social, que ao longo dos anos vem se mostrando cada vez mais insuficiente para uma vida digna. (BRONSTRUP; BECKER, 2016, p.20). 
Assim como somos educados por nossos pais durante um período longo de nossas vidas, de modo que, aprendamos a nos posicionar diante das mais diversas situações cotidianas, é evidente que o mesmo ocorra com a Educação Financeira. Afinal, observamos tudo e coletamos informações freneticamente mesmo sem se dar conta que aprendemos a consumir de forma sustentável.

Portanto uma família que tem uma vida financeira controlada, estruturada, e vive em equilíbrio, transmite essas mesmas qualidades às gerações futuras. A intenção dos estudos em Educação Financeira é preparar os jovens para administrarem suas vidas financeiras, pois possuem uma visão positiva, clara e objetiva de seus sonhos, alcançando-os com maestria.

Já o mesmo não acontece com aquelas famílias que vivem em total desacordo com a realidade ao qual pertence. Ganha-se um $X$ e gasta-se $Y$, ou até mesmo o ganho condizente, porém o gasto não acompanha, é desenfreado e muitas vezes desnecessário. Isso vai na contramão da economia e o resultado é um só, seguido de uma palavra que acompanha grande parte da população mundial, a "inadimplência".

Segundo D'Aquino (2008), a Educação Financeira tem por função criar uma base com propriedades na vida da criança de tal modo que venha refletir positivamente na vida adulta, onde percebe-se o real valor do dinheiro, usando de forma apropriada e com responsabilidade, no intuito de educar os jovens para uma maturidade financeira.

Seguindo esse conceito, D'Aquino (2008, p. 11), afirma que "aos cinco anos de idade é possível construir uma base do modelo financeiro para a criança". Em base no que foi dito anteriormente, se não houver um bom entendimento do assunto $\mathrm{e}$ valores que agregam ao conhecimento, tanto faz ganhar $R \$ 50,00$ ou $R \$ 5000,00$.

A quantia não importa é irrelevante se não estiver associada aos valores significativos do bem de consumo. Fica claro a importância da inclusão da Educação Financeira nas escolas desde o início da vida acadêmica. 
Corroborando com isso, foi proposto a Câmara dos Deputados, o projeto de lei n.3.401/2004 (LOBBE NETO, 2004), que trata da criação da disciplina de Educação Financeira nos currículos de $5^{\text {a }}$ a $8^{\underline{a}}$ séries do Ensino Fundamental e do Ensino Médio. (BRONSTRUP; BECKER, 2016, p.22).

Contudo, o projeto não se firmou em seu formato original, e em 2009, um projeto da Câmara de Lei n. 171/2009 (LOBBE NETO, 2009), determina que Educação Financeira seria um tema integrado ao currículo da disciplina de Matemática.

Com a aplicação da Educação Financeira, as novas gerações de alunos serão capazes de utilizar o dinheiro de forma consciente, e aprenderam que não se trata apenas disso, pois é mais abrangente. Se pararmos para pensar, fica fácil perceber outros conceitos inseridos na Educação Financeira, tais como, sustentabilidade e o impacto econômico social e ambiental, entre outros.

Com o consumo consciente, haverá diminuição na compra de produtos desnecessário, evitando a compra compulsiva que por sua vez acaba levando ao endividamento e pôr fim a inadimplência que vem mostrando índices alarmantes.

Outro fator a ser considerado, sãos as propagandas dos mercados, lojas e tudo mais que engloba o comércio que induzem os consumidores a gastar cada vez mais, com ofertas e promoções com descontos de porcentagens já embutidos nos produtos e de pagamentos facilitados.

O papel da Educação Financeira é transmitir uma relação equilibrada entre indivíduo/dinheiro, ajudando a tomar as melhores decisões a curto, médio e longo prazo. " [...] deve ser vista como um conjunto de hábitos financeiros saudáveis que contribuam para melhorar a situação, o proveito e as perspectivas financeiras das pessoas." (MODERNELL, 2011, p. 22).

Em 2004, a Serasa Experian fez uma pesquisa sobre a inadimplência e contatou um número muito grande de pessoas endividadas, atribui-se a uma das causas a falta de planejamento financeiro, decorrente da falta da Educação Financeira, outro fator relevante a se considerar são os momentos difíceis, tais como óbito na família, onde 
requer uma atenção especial e poucas pessoas estão preparadas para essa situação cobertas por um plano funerário.

A pesquisa feita nas regiões brasileiras, apontou para a Região Norte com o maior índice de inadimplência, 31,1\% da população, em seguida a Região Centro-Oeste com $26,4 \%$ e a faixa etária está entre 26 e 30 anos. Ao longo dos anos percebeu-se o aumento da inadimplência. No ano de 2009 a 2010 a Serasa Experian registrou um aumento de 6,3\%, já nos anos de 2014 a 2015 foi registrada uma alta de 16,7\%.

O total de inadimplentes, pessoas com contas em atraso, ficou em 63,8 milhões em novembro de 2019, ante 62,6 milhões registrados em igual mês de 2018. Os dados foram divulgados hoje (21) pela Serasa Experian. (AGÊNCIA BRASIL SÃO PAULO, 2020).

As dívidas negativadas, contas atrasadas ou não pagas, geram uma inclusão em instituições de proteção ao credito como por exemplo, a Serasa e o SPC (serviço de proteção de crédito), impossibilitando o consumidor de obter empréstimo, financiamento, entre outros, que só saíram da lista de inadimplentes mediante o débito.

Apesar do alto índice de inadimplência, uma pequena parcela da população já está organizando sua vida financeira de modo a sanar as dívidas, ou como se diz, "limpar o nome “ (uma expressão muito usada no cotidiano), através de feirão de renegociação ou diretamente nas instituições ao qual devem. Contribuindo dessa forma positiva para a economia, onde o dinheiro volta a circular e a economia cresce.

\subsection{EDUCAÇÃO FINANCEIRA NO BRASIL}

O Brasil por ser um país subdesenvolvido com grande abismo social, a maioria da população não recebeu de seus pais a base de uma Educação Financeira adequada, resultando em endividamentos.

Foi realizada uma pesquisa pela S\&P Ratings Services Global Financial Literacy Survey (Pesquisa Global de Educação Financeira da divisão de rating e pesquisas 
da Standard \& Poors) onde o Brasil ocupou $74^{\text {a }}$ posição no ranking global de nível de educação financeira.

Em relação a cultura financeira no país o Brasil apresenta de $25 \%$ a $34 \%$ de adultos financeiramente alfabetizados, esse baixo índice é devido a crises, inflações, problemas gerados pela corrupção e outros fatores que contribuem de forma negativa para que o país tenha um desenvolvimento financeiro.

Esse fato mostra que o brasileiro não sabe lidar com o dinheiro e consequentemente a inclusão ao sistema financeiro independente da classe social pouco acontece.

Em 2010, a partir do Decreto Federal n 7.397/2010, foi instituída a Estratégia Nacional de Educação Financeira (ENEF) que consiste na divulgação e implementação da Educação Financeira no Brasil, permitindo aos cidadãos fazerem decisões financeiras.

Um dos primeiros projetos da ENEF foi um programa de Educação Financeira para escolas públicas e foi desenvolvido em colaboração com o Ministério Federal da Educação e Secretarias Estadual e Municipal da Educação.

Conclui-se que além dos incentivos da ENEF e da Educação Financeira na escola, os pais devem ensinar aos filhos a importância de organizar a vida financeira com disciplina e competência para que prosperem financeiramente no futuro.

Segundo Cerbasili (2011, p. 36), nas diversas atividades familiares que incluam algum tipo de atividade financeira, o envolvimento das crianças será obtido se elas demonstrarem facilidade em acompanhar a matemática simples da economia doméstica, ou se souber diferenciar os preços das coisas de seu efetivo valor.

\subsection{PROPOSTA DE INTERVENÇÃO}

Planejar uma proposta de intervenção é construir algumas estratégias para que o aluno seja capaz de superar as dificuldades geradas pela má educação financeira gerada por nossa sociedade. 
O papel do docente é fundamental ao organizar estratégias pedagógicas, para que o aluno obtenha um aprendizado financeiro com êxito.

A seguir, apresentaremos algumas propostas de intervenção significativas para a educação infantil, nível fundamental, nível médio e até para os pais dos alunos.

Educação Infantil

O professor pode propor uma peça teatral apresentada pelos próprios alunos baseada na história do livro de educação financeira infantil "A Economia de Maria" da autora Telma Guimarães Castro Andrade.

Logo após a apresentação da peça, o professor deve explicar utilizando uma didática eficaz sobre quais são os benefícios que a economia do dinheiro proporciona para os pequenos. Incentivando a compra de um cofrinho e a guardar um valor $\mathrm{X}$ por mês.

O professor deve pedir para os alunos trazerem todo mês o seu cofrinho, para averiguar se os alunos estão conseguindo economizar. 
Figura 1- A Economia de Maria

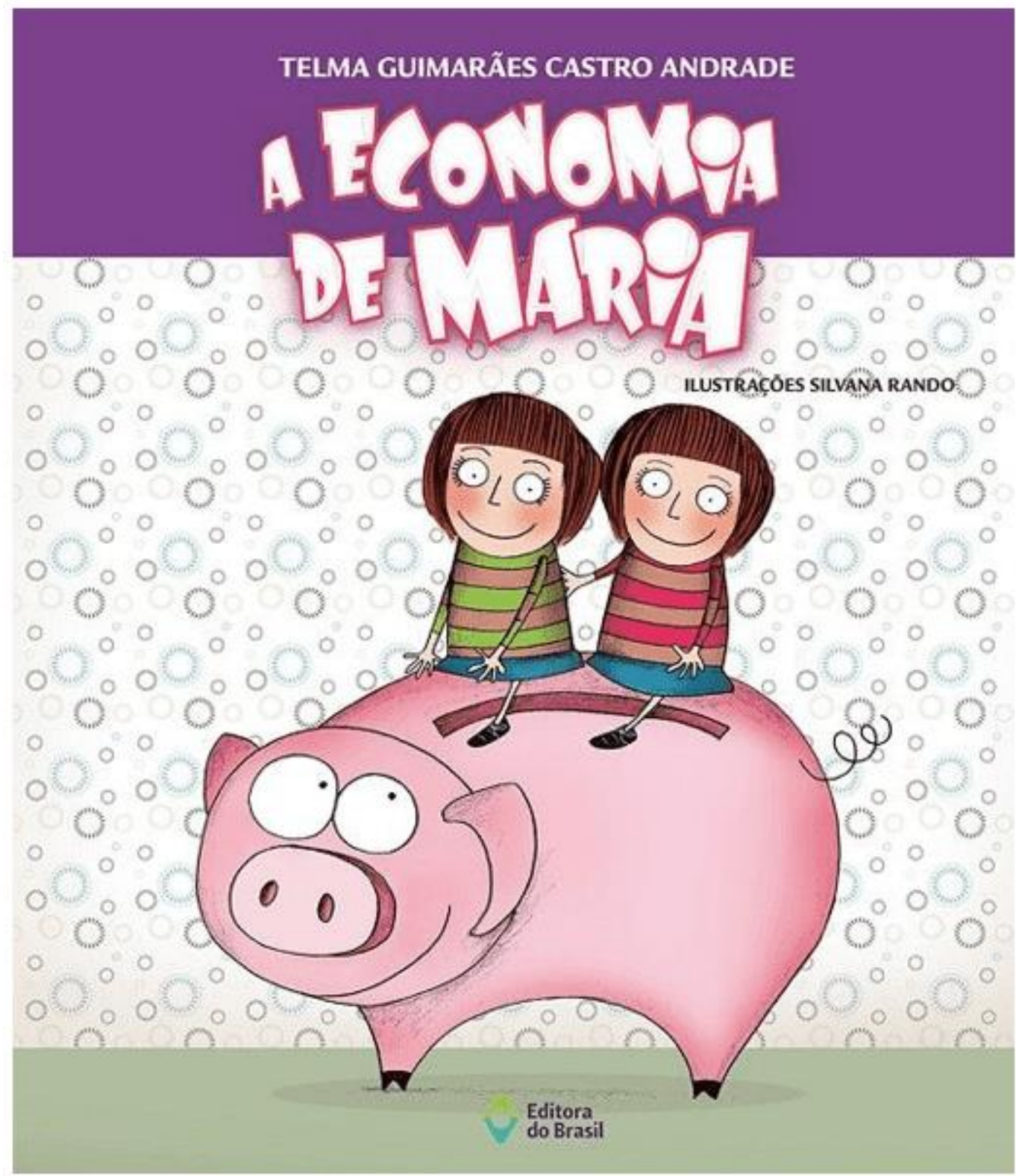

Fonte: passeidireto.com

A sinopse se baseia na história das irmãs gêmeas Helena e Maria que ganharam lindos cofrinhos da madrinha. Mas, Helena não quer guardar dinheiro, comprando tudo o que deseja, enquanto Maria desde pequena já sabe poupar, percebendo a importância de poupar. 
A autora utiliza uma narrativa simples e envolvente para demonstrar valores importantes para a formação financeira infantil como saber gastar sem exageros é a melhor forma de lidar com o dinheiro. Este divertido livro aborda um tema bastante atual: a Educação Financeira.

Nível Fundamental

Utilizaremos a Modelagem Matemática como uma proposta de intervenção para os alunos de ensino fundamental.

A Modelagem Matemática é uma metodologia para o processo de ensinoaprendizagem que possibilitará ao aluno ser o construtor do seu próprio conhecimento a partir de situações cotidianas, vivenciadas por ele ou pelo grupo que está inserido.

A utilização de atividades de Modelagem Matemática proporciona satisfação pelo diferente e o contato com a realidade pode ser importante para formar o senso crítico, além de tornar o aluno e o professor mais reflexivo.

A modelagem tem sido utilizada como forma de interação entre a matemática formal e a sua utilidade na vida real. Entendem a Modelagem Matemática como:

[...] uma alternativa de ensino-aprendizagem na qual a matemática trabalhada com os alunos parte de seus próprios interesses e o conteúdo desenvolvido tem origem no tema a ser problematizado, nas dificuldades do dia-dia, nas situações de vida. Valoriza o aluno no contexto social que o mesmo está inserido, proporcionando-lhe condições para ser uma pessoa crítica e capaz de superar dificuldades. (CAMPAGNOLLO e SCHEFFER, 1998, p.36).

O papel do professor é ser o alicerce para a construção do conhecimento e que a sua metodologia possa fazer a diferença, motivando os alunos em aprender, tornando o ensino da Educação Financeira mais prazeroso, abordando sempre a realidade como referência, tornando o aluno mais consciente e equilibrado financeiramente. 
(...) uma atividade de modelagem exigirá do professor a disponibilidade para pesquisar, desmistificando o papel centralizador, no qual o docente detém quase que a totalidade do processo de ensino e aprendizagem. Além disso, possibilitará que os alunos contribuam com a aula, fazendo pesquisas e dando sugestões, tornando-se corresponsáveis pela aprendizagem. (PEREIRA, 2010, p.121).

A metodologia da Modelagem Matemática em sala de aula, consiste em algumas etapas que foram sugeridas por Burak (1998), que são: escolha do tema, pesquisa exploratória, levantamento dos problemas, resolução dos problemas e 0 desenvolvimento da Matemática relacionada a Educação Financeira e análise crítica das soluções.

Abaixo seguem as atividades propostas que estarão ligadas as etapas da Modelagem Matemática:

Atividade 1: Escolha Do Tema

Serão propostas pelo professor atividades envolvendo temas da Educação Financeira para que os alunos em grupos, discutam, levantem hipóteses e depois encontrem a melhor solução para os problemas.

Os alunos também irão decidir os valores a serem trabalhados na proposta abaixo:

\section{Atividade 1: Administrando a mesada}

Nilson e Solange são irmãos e ajudam na bicicletaria de sua família. Essa ajuda rende-Ihes uma mesada de $R \$$ por mês a cada um. Eles possuem mensalmente alguns gastos fixos e necessitam administrar esse dinheiro, pois seu pai não Ihes oferece nenhuma ajuda financeira extra durante o mês.

Depois da discussão com os colegas, façam um esquema dos gastos de Nilson e Solange.

Lembrem-se que são os gastos durante o mês todo. 
Os gastos semanais de Nilson são com: cantina da escola ), passeio com os amigos no sábado ) e guloseimas no mercadinho ).

Os gastos semanais da Solange são com: cantina da escola e saída aos sábados com as amigas

Após a elaboração do esquema dos gastos, converse com seus colegas e responda:

1. a) O dinheiro que eles recebem por mês é suficiente para o pagamento dos gastos?

2. b) O que vocês sugerem para que eles gastem somente o que ganham pela ajuda no comércio da família?

Atividade 2: Pesquisa Exploratória

Para iniciarmos, os alunos responderão a um questionário que tem o objetivo de identificar conhecimentos sobre a Educação Financeira pessoal e familiar.

Figura 2- Dinheiro

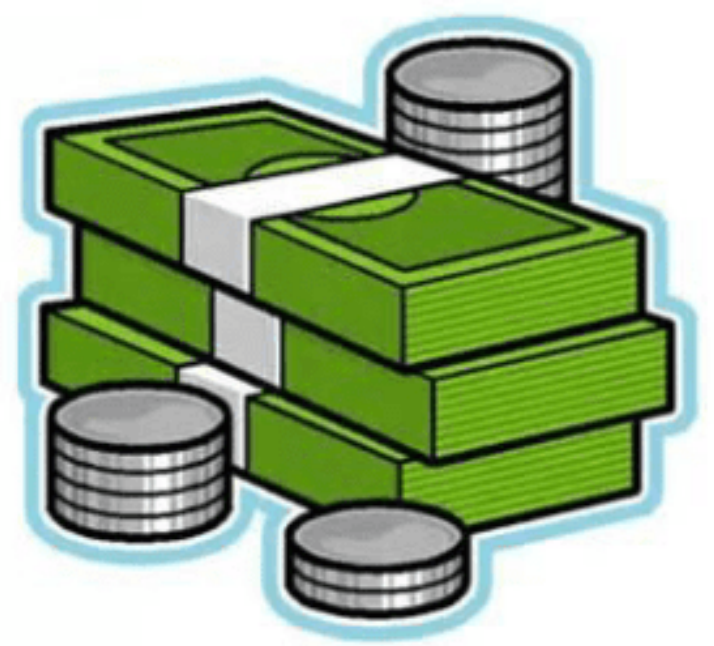

Fonte: http://ganhardinheirourgente.com/wp-content/uploads/2014/09/money.jpg

01) Qual é a sua idade? 
02) Quantas pessoas moram em sua casa?

03) Dentre elas, quais recebem algum tipo de renda (salário, pensão, aposentadoria, benefícios entre outros)?

04) Para você, o que é dinheiro?

05) Quem da sua família Ihe dá dinheiro?

( ) pai

( ) mãe

( ) avó

( ) avô

( ) outros

06) O que você faz com o dinheiro que ganha?

07) Como a sua família realiza os pagamentos de contas, enumere de acordo com as opções (1) à vista e (2) a prazo:

( ) supermercado

( ) vestimentas

( ) luz

( ) água

( ) medicamentos

( ) gás 
08) Sua família costuma fazer pesquisa de preço a fim de procurar produtos mais baratos?

09) Sua família tem o hábito de fazer economias? Se a resposta for sim, para que fim se utiliza tais economias?

10) A família costuma se reunir para decidir sobre os gastos a serem feitos?
( ) $\operatorname{sim}$
( ) não

11) Sua família acompanha os gastos mensais através de:

( ) caderneta de anotações

( ) planilha/tabela de gastos

( ) fatura do cartão de crédito

( ) extratos bancários

( ) comprovantes de débitos

( ) não acompanha

( ) outros

12) Você já teve ou tem um "cofrinho" para guardar as suas economias?

13) O que você e sua família sabem sobre Educação Financeira?

Com o objetivo de favorecer aprendizagens necessárias aos alunos sobre a Educação Financeira, bem como, incentivar a prática da leitura devem ser realizadas as leituras de alguns livros que abordam o tema como por exemplo os citados abaixo: 
Figura 3- Os livros

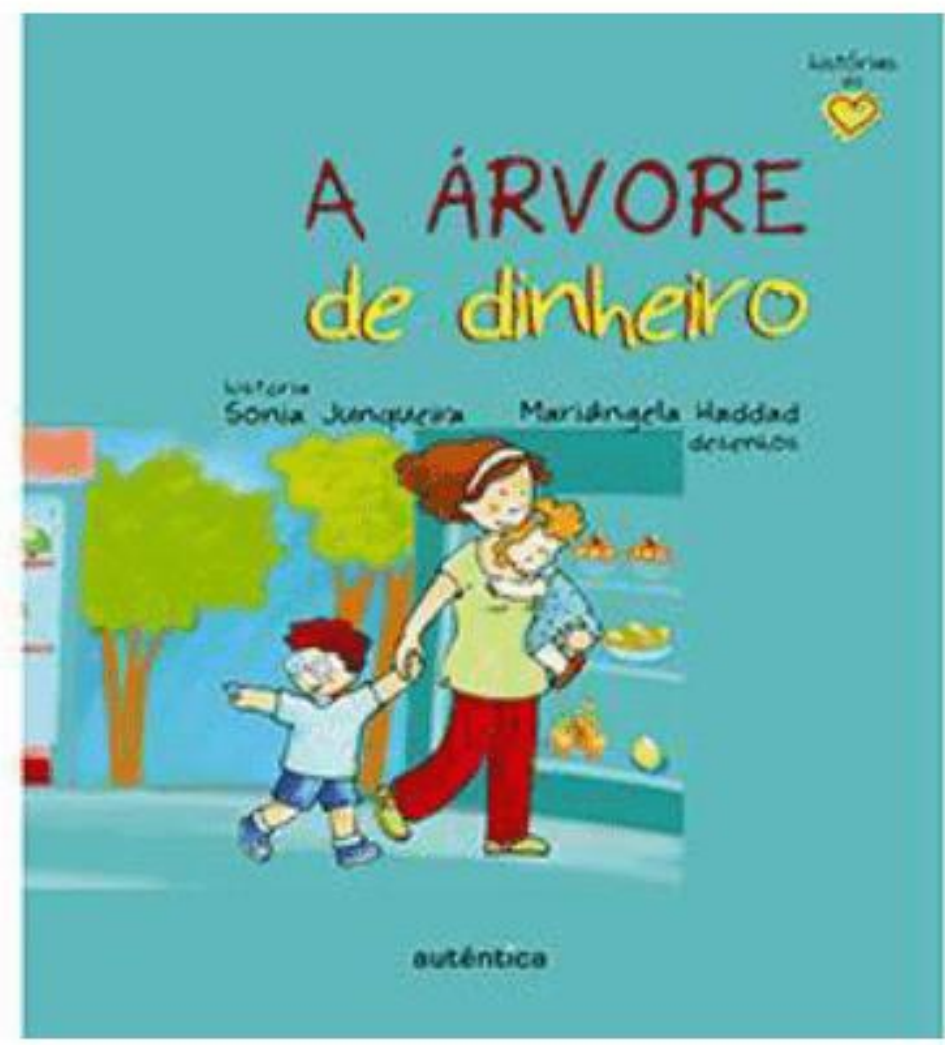

Fonte: amazon.com.br

RC: 85316

Disponível em: https://www.nucleodoconhecimento.com.br/educacao/campo-escolar 


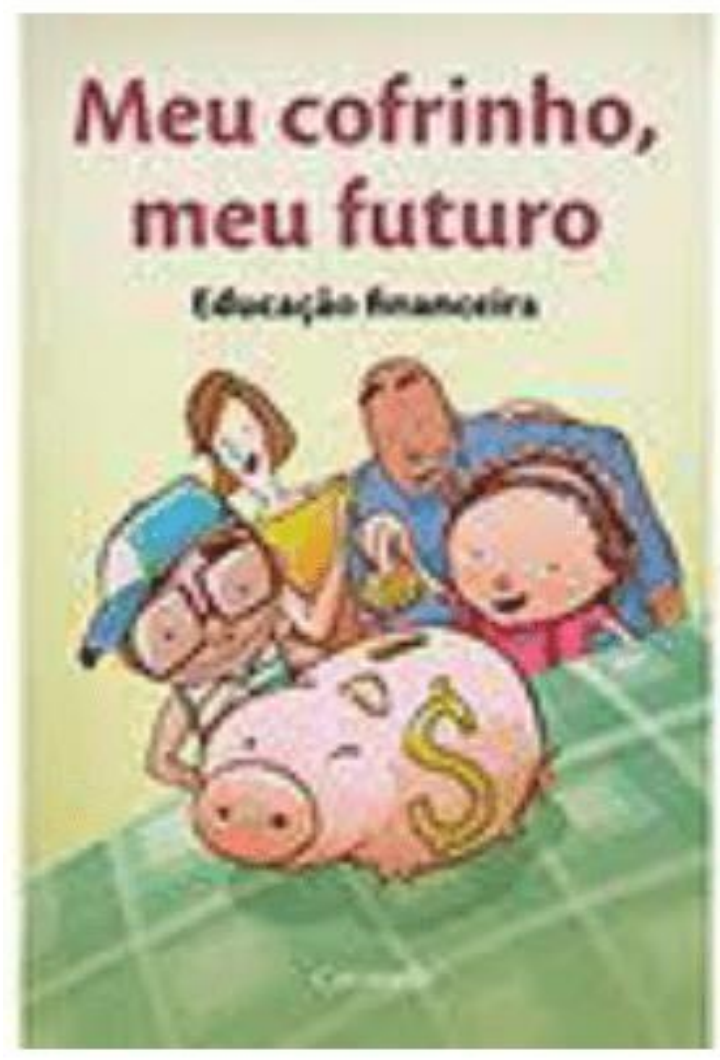

Fonte: saraiva.com

RC: 85316

Disponível em: https://www.nucleodoconhecimento.com.br/educacao/campo-escolar 


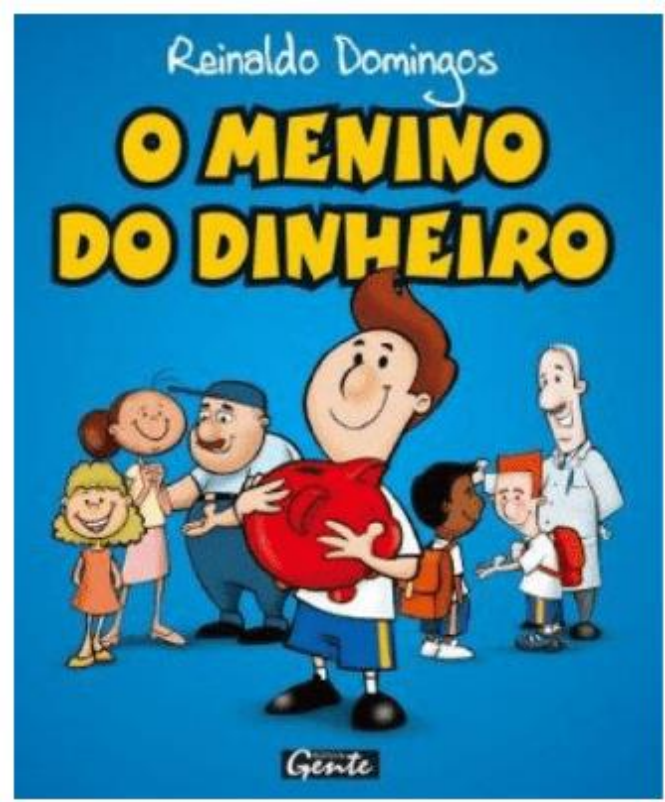

Fonte: WWW3.livrariacultura.com.br

Após a leitura, responda as seguintes questões:

- Qual é o título do livro que você escolheu?

- Em que local ocorre a história?

- Quais são os personagens da história?

- Que acontecimento gerou toda a história?

- Como se resolveu essa situação?

- Já aconteceu com você, situação parecida com a da história? Conte o que

- O que você diria a seus amigos sobre esse livro?

- O que você mais gostou no livro? Por quê?

- O que não gostou? Por quê?

- Que conhecimentos você adquiriu ao ler o livro?

Atividade 3: Levantamento Dos Problemas

Para ter controle das receitas e despesas de uma residência, uma dica muito importante é a documentação de todos os gastos de uma forma rápida e eficaz, o que irá te ajudar a ter mais disciplina e a possuir uma visão geral de como a renda está distribuída. Preencher uma tabela ajuda a visualizar e ter um controle dos seus 
gastos, bem como, verificar de uma forma geral se existe a possibilidade de fazer alguns ajustes para economizar. Essa tabela vamos chamar de orçamento doméstico, e deve conter os seguintes itens: mês, renda mensal, alimentação, moradia, educação, saúde, transporte, lazer, água, luz, internet, outro.

Figura 4- Calculadora

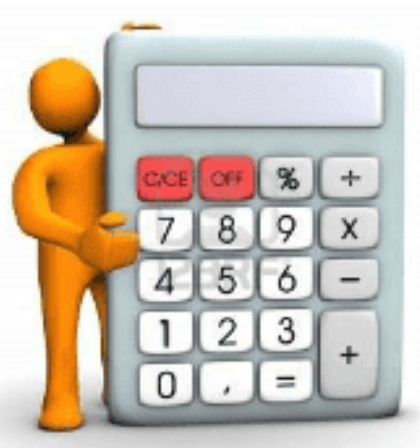

Fonte: http://4.bp.blogspot.com/-vu4bXe8Oczs/T-

8XBvReotl/AAAAAAAAAXw/neTpRZqQyo4/s1600/calculadora1.jpg

Atividade 4: Resolução Dos Problemas

Aprenda A Fazer O Seu Orçamento

Para fazer o orçamento serão dadas algumas dicas básicas, porém podem surgir sugestões dos alunos de alguns itens também importantes para a realização da tarefa.

- Se você possui uma renda mensal, divida-a em semanas, isso o ajudará a se planejar melhor quanto ao seu orçamento;

- Semanalmente faça uma lista de seus gastos fixos, como transporte e lanche;

- Depois, faça uma lista do que você deseja, como: tomar um sorvete e comprar um livro; 
- Agora, liste as coisas que você irá precisar poupar para comprar aquilo que você tanto deseja;

- Diminua das suas despesas fixas e necessárias do total de sua renda. O resultado é chamado de saldo, o qual você poderá gastar ou poupar para comprar algo futuramente.

Veja um exemplo prático:

No orçamento semanal, de uma renda de ( $R \$ 15,00)$, eu tenho despesas fixas com transporte $(R \$ 5,00)$ e lanche da escola $(R \$ 5,00)$. O total de gastos necessário é de $(R \$ 10,00)$ e meu saldo é de $(R \$ 5,00)$. O que desejo comprar é um sorvete $(R \$ 4,00)$ e um livro $(R \$ 15,00)$

Posso tomar o sorvete no final de semana e ainda sobra $R \$ 1,00$ para economizar e comprar o livro. Se quiser o livro o mais breve possível, preciso economizar no lanche da escola ou deixar de tomar o sorvete no final de semana.

O professor pode propor ao aluno elaborar um orçamento mensal com a família contendo os gastos fixos como: alimentação, água, luz, telefone, aluguel, prestações entre outros, e com outros possíveis gastos, como vestuários e medicamentos, por exemplo. Não esquecendo de somar os possíveis gastos e depois diminuir da renda, a fim de verificar se existe a possibilidade de poupar algum dinheirinho para realizar algum desejo de família.

\subsection{PESQUISA DE CAMPO}

A partir desse ponto, será apresentado dados de uma pesquisa de Educação Financeira aplicada em uma escola privada de Ensino Fundamental situada no município de Santa Maria - RS. Participaram da pesquisa para a análise a direção, professores e alunos. Sendo um total de onze professores, oitenta e três alunos, aos quais quarenta e cinco encontram-se no sétimo ano, vinte e cinco no oitavo ano e treze alunos no nono ano do Ensino Fundamental. 
O discernimento dos professores e do diretor, referente ao tema da Educação Financeira e sua inclusão ao meio acadêmico, também foi avaliado. A pesquisa realizada apresenta várias etapas, entre elas o estudo exploratório; com a finalidade de expandir, elucidar e remodelar conceitos; o estudo de casos, onde a pesquisa é aprofundada sobre um ou poucos objetos de investigação, de modo a produzir conhecimento amplo e detalhado sobre o tema, coleta de dados; onde as informações são de natureza qualitativo-quantitativo e também a utilização de um questionário com perguntas elaboradas estrategicamente para a pesquisa, contendo algumas perguntas fechadas e outras com alternativas no intuito de auxiliar nas respostas para uma análise minuciosa.

Essa análise tem por finalidade revelar qual a intensidade do conhecimento do aluno mediante a Educação Financeira de modo a saber de onde provém o entendimento sobre o tema. E para os alunos que não possuem tal conhecimento, o tema ficou em aberto, para ver o grau de interesse do alunado.

De acordo com a pesquisa feita com o diretor responsável pela instituição, a Educação Financeira está inserida na grade curricular há mais de dois anos e foi apresentado pelos professores que destacam a importância em se ter o conhecimento do assunto, contudo há necessidade de um preparo pedagógico condizente e efetivo para alcançar bons resultados na aprendizagem.

Já com os professores do Ensino Fundamental que participaram da pesquisa, foi realizado um questionário de caráter avaliativo sobre o tema Educação Financeira, sendo que participaram desse questionário 73 professores de várias áreas entre elas, Língua Portuguesa, Língua Espanhola, Língua Inglesa, Ciências, Geografia, História, Ensino Religioso, Produção de Texto e Matemática.

Com exceção da última disciplina citada, os demais poucos contribuem para a Educação Financeira. Constatou que $18 \%$ não tinham conhecimento e os $82 \%$ restantes ficaram divididos entre os que possuíam algum conhecimento e os que realmente entendiam do assunto. 
Com base nos dados obtidos pelo questionário, $55 \%$ das disciplinas abordam o tema e $50 \%$ desses professores participaram de cursos presenciais ou online para o preparo de sua aula enquanto a outra metade buscou informações por meio da televisão, jornais, revistas, internet, entre outros.

Conforme dados da pesquisa, constatou-se que aproximadamente $90 \%$ dos Educadores adquiriram conhecimento sobre o assunto no período de suas infâncias com seus pais e parentes, ouvindo-os e conversando em família. Outra forma de adquirir o conhecimento é através dos professores abordando o tema em salas de aula.

Todos os professores entrevistados ressaltaram que a Educação Financeira é proeminente, sendo que $64 \%$ são a favor da inclusão nas escolas e $36 \%$ acham importante tratar do tema. Sobre o entendimento dos Educadores, os alunos demonstram interesse ao assunto e uma estratégia para abordar o tema e prender o foco do alunado é através de aulas práticas aguçando a curiosidade e o ensinoaprendizagem torna lúdico e prazeroso.

De acordo com a pesquisa, $57 \%$ dos alunos são do sexo masculino e $43 \%$ feminino. Os pais que concluíram o Ensino Médio, correspondem a 42 sendo a maioria, 39\% com Ensino superior e 7\% com Ensino Básico Incompleto. A seguir dados da pesquisa do alunado quanto ao grau de conhecimento sobre a Educação Financeira.

Dos alunos do sétimo ano, apenas 10\% apresentavam lucidez referente ao tema, quase metade, $47 \%$ responderam ter algum conhecimento, $25 \%$ não sabiam nada a respeito e 18\% não souberam opinar. Fica claro que mais da metade dos alunos do sétimo ano não tem discernimento sobre o assunto Educação Financeira.

O mesmo não ocorre nas outras séries, oitavo e nono ano, onde $56 \%$ e $61 \%$ dos alunos tem o conhecimento da Educação Financeira. Segundo a pesquisa, há uma desigualdade entre as séries do Ensino Fundamental quando se refere ao tema abordado em salas de aula, $69 \%$ dos alunos do nono ano e $72 \%$ dos alunos do 
oitavo ano tiveram o conhecimento da Educação Financeira através dos professores.

Isso não acontece com a turma do sétimo ano, apenas 33\% desses alunos obtiveram contato com o tema. O fato é que eles não tiveram acesso ao estudo em sala de aula, pois segundo a instituição, o tema seria abordado no terceiro semestre do ano letivo e a pesquisa ocorreu no início do primeiro semestre de 2016.

Outro aspecto a ser analisado, é o entendimento do quão importante e benéfico é a comunicação sobre o tema financeiro entre pais e filhos. Levando em consideração que esse tema é recente, e que são poucos os pais que obtiveram contato quando eram crianças, é necessário conhecer e aplicar na vida diária, como reflexo das necessidades demandadas no seu dia a dia. (BRONSTRUP; BECKER, 2016, p. 31).

Contudo a pesquisa informa que $64 \%$ dos alunos adquiriram algum entendimento sobre Educação Financeira por meio das redes sociais entre outras e a grande maioria dos entrevistados apoiam a inclusão do tema na grade curricular pois a instituição possui um ambiente favorável para a aplicação significativa do assunto em questão. Por outro lado, existem aqueles que consideram o tema inapropriado para um debate em salas de aula, cerca de $6 \%$ do alunado.

As opiniões entre os alunos referente ao tema é muito divergente, entretanto, a maioria reconhece tamanha importância em ir a finco no assunto, pois o conhecimento adquirido hoje refletirá nas suas ações futuras, impactando na formação de cidadãos com conhecimento para consumir de forma sustentável.

Outro fator preocupante é o fato dessa nova geração não ter discernimento do real valor do dinheiro e do poder de compra. Tão pouco associam o valor do dinheiro em mãos com o valor da mercadoria que compram ficando perdida sem saber se o dinheiro em questão é suficiente para quitar o débito.

Isso serve para reforçar a importância em incluir nas grades curriculares 0 conhecimento em Educação Financeira como matéria a ser aplicada, discutida e praticada em salas de aulas e capacitar os Educadores já inseridos nas instituições 
que ministram aulas, bem como capacitar as futuras gerações que escolheram como profissão o ofício de ser professor.

\subsection{INADIMPLÊNCIA}

Em pleno século XXI, o número de endividados é astronômico, um mal que assola a humanidade. Uma simples dívida que não é quitada, deixada de lado por ter um valor baixo, ou ainda a falta de dinheiro ou por alguma outra razão, pode se tornar um caos, tomando proporções catastróficas que foge do nosso controle, vira uma "bola de neve", só aumenta.

Contudo, há crescimento nas estratégias voltadas a sanar esse mal, a Educação Financeira é uma delas. Um destaque internacional fica a cabo da Organização para a Cooperação e Desenvolvimento Econômico (OCDE). Essa instituição desde 2003 junto a outros países, criam iniciativas para promover a inclusão da Educação Financeira, destacando sua importância em melhorar o comportamento financeiro individual e melhorar a conduta frente ao comércio.

.... Conduzir as condutas dos indivíduos, de modo a torná-los prudentes no trato com o dinheiro e capazes de assumir a responsabilidade de gerir suas finanças com autonomia, mesmo nas situações mais adversas (SARAIVA, 2017, p.159).

Gastar é algo inevitável, pois precisamos nos abastecer de produtos. É necessário um olhar crítico de acordo com a demanda do que realmente se precisa ter, e comprar de maneira inteligente. Uma compra é consciente quando o dinheiro é gasto de forma inteligente com o intuito de beneficiar-se de curto a longo prazo.

O consumidor através da Educação Financeira, passa por um processo de conselhos objetivos, informações e instruções, onde compreende e aprende a associar conceitos financeiros e produtos, desenvolve habilidades para tornar-se mais consciente das finanças e dos riscos, consequentemente optar pela melhor escolha do seu bem-estar financeiro.

Frente a esse cenário, observa-se que cresce o número de iniciativas nacionais para mobilizar estratégias de Educação Financeira não 
apenas junto às escolas, mas também com vistas a atingir um público mais amplo por meio de ações que não estejam ligadas às instituições de educação formal (SARAIVA, 2017, p.159).

Outra estratégia para evitar a inadimplência, é guardar um percentual do ganho mensal. Ter uma poupança onde possa depositar uma quantia estabelecida todo mês que pode ser de grande ajuda a longo prazo ou quando se fizer necessário o uso desse valor. No entanto, deve-se ter em mente que essa estratégia ajuda a equilibrar as finanças e para tal é fundamental que haja coerência com o consumo e os gastos do dia a dia.

Agora na contramão de uma realidade estável, chega o mal que assola a população mundial, um novo vírus, uma pandemia "Covid-19" que está espalhando rapidamente e tornando a vida das pessoas um caos. Notícias a todo momento divulgam novos acontecimentos sobre o assunto em tempo real e como se prevenir do vírus. $\mathrm{E}$, diante de todo esse caos, a população começa a abastecer-se de todo tipo de produtos, estão estocando alimentos, produtos de higiene entre outros.

É fato que no comércio houve um aumento considerável de consumidores, tal situação alavancou as vendas de gênero de primeira necessidade. Como esse artigo tem o foco na Educação Financeira, fica uma pergunta no ar: Essa grande massa que esta estocando mantimentos, se precavendo do pior, terá condições de sanar as dívidas posteriormente?

Ou ainda, estavam preparados financeiramente para uma situação de tamanha magnitude? Pouparam dinheiro ao longo de suas vidas? Esse acontecimento se encaixa nos fatos inesperados que requerem uma postura frente ao uso do dinheiro. Outra pergunta a ser feita é: Os consumidores estão comprando de forma consciente ou desordenadamente?

As Mídias também divulgaram locais onde o comércio parou devido ao risco de contaminação entre outras medidas que o governo vem tomando frente a essa pandemia, com isso o comércio que abrange essa área de isolamento fica inativo. 
Para a população que é desprovida da tecnologia e do conhecimento de seu uso para a quitação de dívida, cabem outras perguntas:

Terá juros? Como essas pessoas devem proceder para sanar o débito extra decorrente do surto que assola o mundo?

\section{CONSIDERAÇÕES FINAIS}

O presente artigo mostra a importância da Educação Financeira para a vida de qualquer pessoa.

Ressalta a necessidade de capacitar o aluno desde o início da sua vida escolar com propostas de intervenção adequadas com objetivo de aprender a origem do dinheiro, como gastá-lo, como poupá-lo e assim descobrir que a Educação Financeira é fundamental para a economia.

Esperamos que essa pesquisa sirva como fonte de inspiração para estimular o crescimento intelectual financeiro de cada aluno, que proporcionará o seu sucesso financeiro para a vida inteira. E nós professores possamos ser os verdadeiros mestres dessa educação financeira de qualidade para que os alunos se tornem adultos mais conscientes quanto as suas finanças, obtendo uma relação equilibrada com o dinheiro e assim formando cidadãos íntegros.

\section{REFERÊNCIAS}

ANDRADE, Telma Guimarães. A Economia de Maria. Editora do Brasil. Editora do Brasil, 1aㅡ Edição-São Paulo, Ano 2010.Coleção coisas de criança. ISBN: 978-85-1001042-9.

BRONSTRUP, Tatiéli Monique; BECKER, Kalinca Léia. Educação Financeira nas escolas: Estudo de caso de uma escola privada de ensino fundamental no município. Disponível em:<http://www.coral.ufsm.br/seminarioeconomia/images/anais_2016.pdf>.Revista 
CAMINE: Caminhos da Educação,Franca,v.8,n.2,2016.ISSN 2175-4217.Acesso em:03/03/2020.

DA CRUZ, Daniele Barbist; DE OLIVEIRA, Fernanda Couto Elisangela; BARVIK, Janete Sena; CARNEIRO, Thayse Machado; PEREIRA, Tatiana dos Santos. Educação Financeira para crianças e adolescentes na região metropolitana de Curitiba. Disponível em: <http://www.portal.estacio.br/media/3728718/educaçãofinanceira-para-crianças.pdf>. Ano 2017.Acesso em: 03/03/2020

D'AQUINO, Cássia. Educação Financeira: Como educar seu filho. Coleção Expo Money,2ªedição-Rio de Janeiro, Ano 2008.ISBN 978-85-352-2421-4.

DOMINGOS, Reinaldo. Coleção DSOP de Educação Financeira. 5ano do Ensino Fundamental-3를 edição-São Paulo: Editora DSOP.ISBN: 978-85-8276-229-5.

MAZEPA, Elza; PEREIRA, Emanueli. A Educação Financeira no contexto escolar: Uma proposta de modelagem matemática. Disponível:< http://www.diaadiaeeducação.pr.gov.br/portals/pdebusca/produções_pde/2016/2016 _artigo_mat_unespar_uniaodavitoria_elzaantoniamazepa.pdf>. Ano 2016.Acesso em:06/03/2020.

MAZEPA, Elza; PEREIRA, Emanueli. Os desafios da Escola Pública Paranaense na perspectiva do professor. PDE-Produções Didático-Pedagógicas 2016 Volume II-Versão Online.ISBN 978-85-8015 0940.

Disponível:<http://www.diaadiaeeducação.pr.gov.br/portals/pdebusca/produções_pd e/2016/2016_artigo_mat_unespar_uniaodavitoria_elzaantoniamazepa.pdf>. Ano 2016. Acesso em: 06/03/2020.

SARAIVA, Karla Schuck. Os sujeitos endividados e a Educação Financeira. Disponível em: <http://www.redalyc.org/articulo.oa¿id=155054210010>Educar em Revista, num.66, out-dez,2017, pp.157-173.ISSN:0104-4060. Acesso: 07/03/2020.

Enviado: Outubro, 2020. 
Aprovado: Maio, 2021.

RC: 85316

Disponível em: https://www.nucleodoconhecimento.com.br/educacao/campo-escolar 